rev.relac.int.estrateg.segur.6(2):35-62,2011

\title{
APROXIMACIÓN A LA PERSPECTIVA JURÍDICA DE LAS DECISIONES DEL PARLAMEN- TO ANDINO EN LOS ORDENAMIENTOS JURÍDICOS DE LOS ESTADOS ANDINOS*
}

\author{
Carolina Blanco Alvarado**
}

\section{RESUMEN}

La Comunidad Andina (CAN) debe responder al principio de la Tridivisión de poderes, en cuanto a la búsqueda de un equilibrio institucional dinámico, que asegure un ejercicio razonable de las atribuciones y competencias otorgadas a los órganos comunitarios y la democratización del proceso andino de integración. Bajo la citada contextualización, el Parlamento Andino intenta asimilarse a las funciones propias de los Legisladores Internos de los países miembros, motivo por el cual resulta de interés aproximarse a la influencia de las Decisiones del Parlamento Andino en los ordenamientos jurídicos de los Estados Andinos.

* El presente artículo es producción académica del Proyecto de Investigación: "El Carácter Vinculante de las Decisiones del Parlamento Andino", el cual finalizó el 30 de Julio de 2011, realizado con el apoyo estructural y financiero de la Universidad Antonio Nariño, Sede Bogotá, Colombia.

** Abogada de la Universidad Externado de Colombia. Magister en Derechos Fundamentales - Universidad Carlos III de Madrid, España. Especialista en Derecho Constitucional- Centro de Estudios Políticos y Constitucionales de Madrid, España. Especialista en Derecho Administrativo - Universidad del Rosario - Bogotá, Colombia. Docente de la Universidad Libre - Bogotá. Docente de la Universidad Santo Tomas. carolinablancoalvarado@hotmail.com 
Palabras clave: Decisiones del Parlamento Andino, Ordenamiento Jurídico Interno, Derecho Andino de la Integración

\begin{abstract}
The Andean Community (CAN) must act in response to the principle of a three-way division of power, in terms of arriving at a dynamic institutional balance that ensures a reasonable exercise of the power and authority granted to the Community institutions and the democratization of the Andean integration process. Under the above contextualization, the Andean Parliament attempts to assimilate the functions of the domestic legislation of the member countries, which is why it is interesting to approach the influence of the decisions of the Andean Parliament in the legal system of the Andean States.
\end{abstract}

Key Words: Decisions of the Andean Parliament, Legal system, Andean Integration Law.

\title{
RESUMO
}

A Comunidade Andina (CAN) deve responder ao princípio da Tri-divisão de poderes no que se refere à busca de um equilíbrio institucional dinâmico, que garanta um exercício razoável das funções e competências outorgadas aos órgãos comunitários e de democratização do processo andino de integração. Sob a mencionada contextualização, o Parlamento Andino tenta se assimilar as funções próprias dos Legisladores Internos dos países membros, motivo pelo qual convém se aproximar da influência de Decisões do Parlamento Andino nos ordenamentos jurídicos dos Estados Andinos.

Palavras chave: Decisões do Parlamento Andino, Ordenamento Jurídico Interno, Direito Andino de Integração.

\section{INTRODUCCIÓN}

La realización de cualquier proceso de integración reclama la estructuración y puesta en funcionamiento de una organización administrativa, y necesita la creación de autoridades comunitarias con competencias normativas y/o direccionales, del mismo modo, la formulación de un sistema normativo con el vigor y la eficacia requeridos para que este pueda regular directamente las cuestiones atinentes a la materia de la integración, la conducta de los países comprometidos y de sus habitantes, sin tener que recurrir a los procedimientos ordinarios del derecho interno de cada país (Tremps, 1994). Lo anterior, ha debido ser el contexto por el 
cual se constituyó al Parlamento Andino como el órgano comunitario deliberante de la Comunidad Andina, y representante de su población.

Si bien, en la realidad fáctica las Decisiones del Parlamento Andino no son obligatorias, principalmente, por los límites de la función normativa del Parlamento Andino y por la falta de voluntad política de los gobiernos andinos, teórica y académicamente dicha realidad no es tan cierta.

El problema jurídico que se va a intentar resolver en estas páginas, es la determinación del nivel de vinculatoriedad de las Decisiones del Parlamento Andino en el ordenamiento jurídico de los países miembros de la Comunidad Andina (CAN). Dicho problema jurídico es de relevancia en el marco normativo de los países andinos, entre otras circunstancias, por los efectos jurídicos que ha generado la globalización del Derecho.

En aras de dar respuesta al referenciado problema jurídico, se analizaron las Decisiones del Parlamento Andino durante el periodo de 2008 a 2010, en concordancia con las actas emitidas por la Plenaria, Mesa Directiva y Comisiones del Parlamento Andino, que sirvieron de soporte a las mencionados Instrumentos Jurídicos. Adicionalmente, se estudió el contenido de las Decisiones del Parlamento Andino en el marco de las Cartas Políticas, de la Jurisprudencia de las Altas Cortes y de las leyes internas.

El anterior ejercicio académico permitió adelantar una investigación cualitativa y cuantitativa, como quiera que con la misma, se pretendió captar la realidad de las declaraciones de voluntad del Parlamento Andino en el marco normativo de los Estados Andinos; y explicar la ubicación de las Decisiones del Parlamento Andino en el Ordenamiento Jurídico de los países miembros, a través de un enfoque de obtención de datos numéricos.

Las presentes paginas pretender analizar la naturaleza de las Decisiones del Parlamento Andino, el grado de implementación de las mismas en la ley interna y en la Jurisprudencia de las Altas Cortes y de las constituciones de los países andinos; finalizando con algunos fundamentos que pretenden determinar por qué dichos instrumentos de voluntad deben ser obligatorios

\section{LA NATURALEZA DE LAS DECISIONES DEL PARLAMENTO ANDINO}

Las Decisiones del Parlamento Andino son actos comunitarios, en razón a la calidad de Órgano Comunitario de dicha Organización. Teóricamente, dichos instrumentos de voluntad son de naturaleza jurídica secundaria y funcional: en primer lugar, porque se encuentran en el marco del Derecho Derivado Comunitario Andino, y en segundo lugar, porque el contenido de las mismas debe ser correlacional a las funciones que explícita o implícitamente le han atribuido los Estados miembros en el Derecho Originario. A pesar de lo anterior, en la práctica, en razón a la tipificación normativa prevista en el Tratado Constitutivo del Parlamento Andino y el Protocolo 
de Trujillo, los Estados miembros y los Órganos e Instituciones del Sistema Andino de Integración (SAI) han considerado a las manifestaciones de voluntad del Parlamento Andino como recomendaciones. Lo anterior dificulta que estas Decisiones ostenten las características propias de las normas comunitarias, esto es, de supremacía y aplicabilidad directa (entre otras).

Gran parte de la Doctrina ha estipulado el carácter no vinculante de las Decisiones del Parlamento Andino, lo cual ha sido reiterado desde los miembros del mencionado órgano internacional, como lo evidencia la ex Parlamentaria Andina, Sandra Yañez, quien ha manifestado la necesidad de lograr que las manifestaciones de voluntad del Parlamento sean vinculantes, lo cual sería el gran paso y la gran conquista regional en la integración regional (Yañez, 2008). En concordancia con lo dispuesto por la citada ex Parlamentaria Andina, la Dra. Ángela Gómez, ha previsto que el Parlamento Andino es un órgano meramente burocrático, que poco o nada puede contribuir al proceso de integración subregional, toda vez que su papel es simplemente de promotor e impulsor y carece de vínculos reales con los otros órganos del Sistema Andino de Integración (SAI), y "no tiene participación directa o indirecta en la toma de Decisiones, no tiene facultad para recibir propuestas ni para proponer" (Gómez, 2010, pp.37 y 39).

En la actualidad, el ámbito de elaboración de la normativa andina se encuentra concentrado, prioritariamente, en dos órganos que dependen directamente de los poderes ejecutivos de los países miembros, esto es, el Consejo Andino de Ministros de Relaciones Exteriores y la Comisión de la Comunidad Andina. En este sentido, y desde una perspectiva exegética, el Parlamentario Andino Juan Mariátegui ha establecido que:

En el proceso de generación de las normas andinas, el Parlamento Andino no tiene facultades de control o supervisión, puesto que tanto el Acuerdo de Cartagena (Artículo 42), como su Tratado Constitutivo (Artículo 1으), lo definen únicamente como órgano deliberante, con la atribución de participar en la generación normativa del proceso mediante sugerencias a los Órganos del Sistema, de proyectos de normas sobre temas de interés común, para su incorporación en el ordenamiento jurídico de la Comunidad Andina; sin capacidad de crear normativa supranacional de carácter vinculante, como son las Decisiones de la Comisión o del Consejo de Ministros de Relaciones Exteriores (Mariátegui, 2009, p.76).

Al respecto, el referenciado Parlamentario establece, que:

[...] al depender la generación de normas comunitarias de los órganos intergubernamentales, automáticamente esta acción queda sujeta a lo que acontece en los países, en lo que respecta al desenvolvimiento de los actores económicos y políticos y a la maraña de intereses sectoriales en cada uno de los países miembros. El Parlamento Andino no debe ser únicamente un órgano deliberante, sino también participar en el proceso de generación de normas, vale decir, convertirse en constituyente andino, con capacidad de codecisión; para ello un proceso de reforma 
institucional debe otorgarle al Parlamento Andino atribuciones de órgano de control, revisión o supervisión de las normas que crean los órganos intergubernamentales de la Comunidad Andina (Mariátegui, 2009, p.76).

Con relación a lo dispuesto por el Parlamentario Juan Mariátegui, resulta pertinente anotar que a pesar de que la Doctrina ha calificado como no vinculantes las Decisiones del Parlamento Andino, es necesario no olvidar que las declaraciones de voluntad del Parlamento, son normas comunitarias, como quiera que son emitidas por un órgano comunitario de la Comunidad Andina (CAN) y, por consiguiente, de aplicación directa en los países miembros, y tienen la posibilidad de reglamentación por parte de los gobiernos nacionales. En este sentido, la Jurisprudencia del Tribunal Andino de Justicia, en concordancia con la Doctrina, reiteradamente ha determinado sobre el alcance vinculante de las Decisiones de los órganos comunitarios, estableciendo que las mismas son eficaces respecto de los Estados a cuyo cumplimiento se destinan, motivo por el cual dichas Decisiones se deben confundir a menudo, con la normatividad interna de los respectivos Estados Andinos (Tribunal Andino de Justicia, 1988).

El Parlamento Andino es un órgano comunitario que si bien no ostenta la competencia clara y expresa de vinculatoriedad de sus Decisiones, ya que no existe Tratado, Acuerdo o Protocolo que lo prevea, y con esto, se puede afirmar la no obligatoriedad de los instrumentos a través de los cuales manifiesta su voluntad; es pertinente recordar que en la estructura orgánica de cualquier proceso de integración, resulta viable la existencia de órganos comunitarios cuyas competencias no hayan sido asignadas expresamente. Para tal efecto, las competencias asignadas a órganos comunitarios pueden clasificarse en explícitas, implícitas e inherentes. En este sentido:

se entiende por competencias explicitas, aquellas previstas expresamente en la respectiva normatividad; por competencias implícitas aquellas que están fuera del texto, son la intención presunta de las partes, los propósitos, finalidades y objetivos del organismo; por competencias inherentes se entienden aquellas que no se contemplaron al dotar a la organización de un marco institucional adecuado sino que aparecen después por decisión de sus propios órganos que las ejercen por considerarlas esenciales para el desarrollo de sus funciones (Magilevich A, 1972, p. 24).

En este sentido, en el marco de los procesos de integración es procedente el reconocimiento de competencias implícitas e inherentes a los órganos comunitarios. Por lo anterior, no es fundamento suficiente el considerar la ineficacia de las Decisiones del Parlamento Andino por la inexistencia de norma expresa que establezca la obligatoriedad de las declaraciones de voluntad del mencionado órgano internacional.

En todo caso, el fundamento por el cual la mayoría de la Doctrina considera a las Decisiones del Parlamento Andino como no vinculantes, obedece principalmente a que el Tratado Constitutivo del mismo, de 1979, prevé que dicho Organismo Internacional se pronunciara a 
través de recomendaciones cuando haga referencia a los propósitos y atribuciones que le han sido encomendados: el Tratado Constitutivo del Parlamento Andino, determina en el Artículo 12, como principales propósitos del mismo: coadyuvar en la promoción y orientación del proceso de la integración subregional andina; promover la participación de los pueblos como actores del proceso de integración andina; fomentar el desarrollo de una conciencia comunitaria andina; y a la vez, en el Artículo 13 del citado Tratado, se prevé como principales atribuciones del Parlamento Andino: examinar la marcha del proceso de integración subregional, y proponer medidas y sugerencias que coadyuven a la aproximación de las legislaciones de las Partes Contratantes.

Resulta contradictorio afirmar que la eficacia de los referenciados propósitos y atribuciones asignados al Parlamento Andino, los cuales son de envergadura en el proceso andino de integración, dependan de instrumentos de voluntad considerados como sugerencias o recomendaciones. Lo anterior, aunado a la tipificación de órgano comunitario al Parlamento Andino, y como consecuencia de ello, a la facultad de expedir Decisiones de carácter obligatorio, permite concluir inconsistencias en la forma de interpretar el Tratado Constitutivo del Parlamento Andino por quienes consideran que las citadas Decisiones no son vinculantes. Adicionalmente, no resulta lógico que las manifestaciones de voluntad del Parlamento Andino se enmarquen como simples saludos a la bandera y menos, cuando se aproxima la consolidación de la elección popular de parlamentarios andinos, lo que sin lugar a equívocos ratificará la legitimidad, validez y obviamente, la obligatoriedad y efectividad de las Decisiones del mencionado Organismo Internacional (Blanco, 2010).

Los órganos e instituciones que conforman el Sistema Andino de Integración (SAI) y los Estados miembros, han interpretado gramatical y exegéticamente el Artículo 14 del Tratado Constitutivo del Parlamento Andino, lo que ha generado que las Decisiones de dicho Órgano Internacional no sean de carácter obligatorio. La anterior perspectiva desconoce la viabilidad de una interpretación sistemática, esto es, aquella "que apele a la búsqueda del sentido de la norma, con ayuda del contexto jurídico en el cual esta se encuentra" (Caballero \& Anzola, 1995, p. 53).

Al respecto, es pertinente anotar que en el ámbito del Derecho Internacional, los Tratados Internacionales pueden ser objeto de interpretación jurídica, cuya función será elegir entre diversas significaciones posibles a un texto, aquella que parezca al mismo tiempo ser la más conforme a los presupuestos respectivos y mejor adaptada a ciertos fines (Vissher, 1963, p. 14).

Es pertinente no olvidar que en el Derecho Internacional existen tres métodos de interpretación: interpretación por el texto, interpretación subjetiva e interpretación teleológica (Moyano, 1985, p. 126). Para efectos de lo dispuesto en estas líneas, se acogerá el método de interpretación teleológica, que ofrece más objetividad en sus resultados, a diferencia de la interpretación subjetiva y por texto, y adicionalmente, por ser un método de interpretación intermedio entre las mencionadas interpretaciones. 
De conformidad con el Método Teleológico, se pretende determinar el propósito general del Tratado, al cual se le atribuye como anota Jiménez de Arechaga:

[...] una existencia propia, independiente del texto y de la intención original de las partes. De esta manera se llenan vacios, se introducen correcciones, los textos se expanden y completan, siempre que sea en ejecución del fin y objeto atribuido al Tratado por el interprete (Jiménez, 1980. P. 57).

Es por lo anterior que dicha interpretación puede convertirse en el vehículo para una interpretación dinámica del Tratado, que se aleja de la voluntad subjetiva de las partes al momento de la celebración del Tratado (Herdegen, 2005, p.136).

Aplicando el método de interpretación teleológica al Tratado Constitutivo del Parlamento Andino, muy seguramente se llegaría a la conclusión de evitar afirmaciones tan categóricas de no considerar la vinculatoriedad de las Decisiones del Parlamento Andino. Si el propósito general de dicho Tratado era constituir en la Comunidad Andina, el Órgano encargado de direccionar el proceso andino de integración, bajo los postulados de una estructura democrática, plural y legítima, para lo cual, normativamente, se le otorgaron propósitos y atribuciones de envergadura dentro del proceso andino de integración; no se puede concluir de manera absoluta, la no obligatoriedad de las Decisiones que emita, y menos, cuando los Estados andinos están a puertas de consolidar la elección directa de parlamentarios andinos en la Región.

Ahora bien, la Doctrina se muestra uniforme en cuanto a que la interpretación de los Tratados Internacionales puede adelantarse de conformidad con principios de interpretación, en este sentido, se procederá a interpretar el Tratado Constitutivo del Parlamento Andino, en lo relacionado al marco normativo de sus Decisiones, de conformidad con los principios de buena fe, efecto útil y de contexto.

La interpretación de los Tratados Internacionales debe ser hecha de buena fe en aras de que la norma pacta sunt servanda no carezca de sentido. En materia del Derecho de los Tratados, la buena fe puede ser entendida, bajo dos sentidos distintos: el subjetivo, que significa, entre otros aspectos, un espíritu de lealtad, de intención recta, de sinceridad que debe predominar a nivel de la conclusión del acuerdo internacional (criterio inseguro porque apela a la intención de las partes); y el objetivo "el cual se considera como un criterio utilizable en la interpretación de situaciones jurídicas nacidas a propósito del Tratado" (Díaz, 1982, p. 171). Es bajo este segundo sentido, en el que resulta pertinente interpretar el Tratado Constitutivo del Parlamento Andino, esto es, atendiendo al contenido del mismo, apelando a una interpretación sistemática y acudiendo a una interpretación articulada de todos y cada uno los artículos que lo conforman en concordancia con los criterios axiológicos que rigen al mencionado Tratado, lo cual permitirá replantear la rigurosidad en la afirmación de no considerar la vinculatoriedad de las Decisiones del Parlamento Andino, en atención a la importancia de las atribuciones conferidas a dicho 
Órgano Internacional por el Acuerdo de Cartagena, y al papel jurídico y político que el mismo debe desempeñar en la Comunidad Andina (CAN).

De conformidad con el principio del efecto útil, "las cláusulas de un Tratado deben ser interpretadas de modo tal que todas ellas tengan un sentido positivo, esto es, que surtan un efecto" (Berberis, 1973, p. 286). En este sentido, no debe considerarse a las Decisiones del Parlamento Andino como simples recomendaciones; de lo contrario, el efecto de las normas del Tratado Constitutivo del Parlamento por las cuales se atribuyen los propósitos y atribuciones a la mencionada Organización Internacional, quedarían sin efecto e impacto en los Ordenamientos Jurídicos de los Estados Andinos. Dicha circunstancia implica el reconocimiento al Parlamento Andino como un órgano del Sistema Andino de Integración (SAI) de carácter eminentemente decorativo, lo cual no corresponde a la lógica de lo que debe ser su papel en la estructura orgánica del proceso de integración andino.

Ahora bien, atendiendo al principio del contexto, la interpretación de los Tratados Internacionales debe hacerse como un todo, esto es, no dando alcance a palabras en forma aislada al tenor del respectivo documento. "Se trata pues de la interpretación de una parte de un Tratado con referencia a todo el contenido del respectivo Tratado Internacional" (Guardia \& Delpech, 1970, p. 316). De esta forma, la tarea de interpretar el Tratado Constitutivo del Parlamento Andino supone no solamente el considerar de manera aislada, la tipificación normativa de recomendaciones a las Decisiones del Parlamento Andino, sino analizar la respectiva norma con las finalidades de dicho Tratado, principalmente, con la protección a la legitimidad que debe imperar en el proceso andino de integración, lo cual conlleva a concluir que de una u otra manera dichas Decisiones deben tener algún grado de obligatoriedad en los Estados Andinos y en la misma Comunidad Andina (CAN)

\section{EL GRADO DE IMPLEMENTACIÓN DE LAS DECISIONES DEL PARLAMENTO ANDINO EN LOS ESTADOS MIEMBROS}

En aras de analizar el grado de implementación de las Decisiones del Parlamento Andino en los ordenamientos jurídicos de los Estados miembros, se contextualizaron dichas Decisiones con las Cartas Políticas, la Jurisprudencia de las Altas Cortes y las leyes internas, concluyéndose que si bien académicamente y teóricamente las Decisiones del Parlamento Andino son de carácter obligatorio, desde la perspectiva fáctica, dichas Decisiones, no cumplen con las características básicas para que se predique su eficacia, esto es, no cumplen con los siguientes presupuestos: (i) no tienen la virtud, fuerza o idoneidad para lograr un determinado objetivo; (ii) no son cumplidas efectivamente; y (iii) se evidencia la inexistencia de sanciones por su incumplimiento. Lo anterior genera como consecuencia que el nivel de implementación de las Decisiones del Parlamento Andino en el ordenamiento jurídico de los países miembros sea deficiente, y no solamente en razón a que dichas Decisiones son 
consideradas como recomendaciones, sino también por los factores que a continuación se proceden a referenciar.

Las Decisiones del Parlamento Andino en el marco de la Ley Interna:

En aras de determinar el grado de implementación de las Decisiones del Parlamento Andino emitidas entre el periodo de 2008 a 2010 en la ley interna de los países miembros, se anexa el siguiente cuadro y se procede con el siguiente análisis el cual intenta corroborar el grado de implementación deficiente:

Tabla 1: Decisiones del Parlamento Andino en el marco de la Ley Interna

\begin{tabular}{|c|c|c|c|}
\hline & & $\begin{array}{l}\text { Número de } \\
\text { decisiones }\end{array}$ & Porcentaje \\
\hline \multirow[t]{2}{*}{1.} & $\begin{array}{l}\text { Decisiones o Declaraciones tenidas en cuenta por los Con- } \\
\text { gresos o Asambleas Legislativas, en su tarea ordinaria legis- } \\
\text { lativa. }\end{array}$ & 0 & $0 \%$ \\
\hline & $\begin{array}{l}\text { Decisiones o Declaraciones en las que no aplica el factor } \\
\text { anterior. }\end{array}$ & 13 & $30.2 \%$ \\
\hline \multirow[t]{3}{*}{2.} & $\begin{array}{l}\text { Decisiones o Declaraciones en la que el Parlamento Andino } \\
\text { debió cumplir compromisos (establecidos en la respectiva } \\
\text { Decisión o Declaración) para lograr su eficacia. }\end{array}$ & 4 & $9.3 \%$ \\
\hline & $\begin{array}{l}\text { Decisiones o Declaraciones en las que el Parlamento Andino } \\
\text { cumplió los compromisos establecidos en las mismas. }\end{array}$ & 0 & $0 \%$ \\
\hline & $\begin{array}{l}\text { Decisiones o Declaraciones en las que no aplica el factor } \\
\text { anterior. }\end{array}$ & 40 & $93 \%$ \\
\hline \multirow[t]{2}{*}{3.} & $\begin{array}{l}\text { Decisiones o Declaraciones cuyo contenido son producto } \\
\text { de la coordinación de los órganos e instituciones que con- } \\
\text { forman el Sistema Andino de Integración (SAI). }\end{array}$ & 0 & $0 \%$ \\
\hline & $\begin{array}{l}\text { Decisiones o Declaraciones en las que no aplica el factor } \\
\text { anterior. }\end{array}$ & 2 & $4.6 \%$ \\
\hline
\end{tabular}




\begin{tabular}{|l|c|c|}
\hline 4. $\begin{array}{l}\text { Decisiones o Declaraciones, cuyo contenido fue producto } \\
\text { del debate entre el Parlamento Andino con los órganos e } \\
\text { instituciones del Sistema Andino de Integración, con com- } \\
\text { petencia en el tema de las mismas. }\end{array}$ & 0 & $0 \%$ \\
\hline $\begin{array}{l}\text { Decisiones o Declaraciones en las que no aplica el factor } \\
\text { anterior. }\end{array}$ & 2 & $4.6 \%$ \\
\hline 5. $\begin{array}{l}\text { Decisiones o Declaraciones en las se evidencia que los Le- } \\
\text { gislativos de los países miembros prefieren la regulación } \\
\text { del contenido de las mismas mediante leyes. }\end{array}$ & 8 & $18.6 \%$ \\
\hline $\begin{array}{l}\text { Decisiones o Declaraciones en las que no aplica el factor } \\
\text { anterior. }\end{array}$ & 35 & $81.3 \%$ \\
\hline 6. & 35 \\
\hline $\begin{array}{l}\text { Decisiones o Declaraciones en las que no existe coordina- } \\
\text { ses miembros y el Parlamento Andino. }\end{array}$ & $81.3 \%$ \\
\hline $\begin{array}{l}\text { Decisiones o Declaraciones en las que no aplica el factor } \\
\text { anterior. }\end{array}$ & 0 & $18.6 \%$ \\
\hline 7. Decisiones o Declaraciones cuyo contenido evidencia le- \\
gitimidad.
\end{tabular}




\begin{tabular}{|c|c|c|c|}
\hline & $\begin{array}{l}\text { Decisiones o Declaraciones cuyo contenido no evidencia } \\
\text { conexión directa, con las funciones del Parlamento Andino }\end{array}$ & 13 & $30.2 \%$ \\
\hline 12. & $\begin{array}{l}\text { Decisiones o Declaraciones que evidencien confusión en- } \\
\text { tre Derecho Internacional y Derecho Andino de la Inte- } \\
\text { gración. }\end{array}$ & 7 & $16.2 \%$ \\
\hline 13. & $\begin{array}{l}\text { Decisiones o Declaraciones que evidencien confusión en- } \\
\text { tre Derecho Internacional Humanitario y Derecho Andino } \\
\text { de la Integración. }\end{array}$ & 2 & $4.6 \%$ \\
\hline 14. & $\begin{array}{l}\text { Decisiones o Declaraciones que evidencien confusión en- } \\
\text { tre Derecho Interno y Derecho Andino de la Integración. }\end{array}$ & 6 & $13.9 \%$ \\
\hline 15. & $\begin{array}{l}\text { Decisiones o Declaraciones cuyo contenido esta reiterado } \\
\text { en leyes emitidas por los Estados miembros de la CAN. }\end{array}$ & 9 & $20.9 \%$ \\
\hline 16. & $\begin{array}{l}\text { Decisiones o Declaraciones cuyo contenido no evidencia } \\
\text { seguimiento por parte del Parlamento Andino, requirién- } \\
\text { dose dicho seguimiento para la eficacia de la respectiva } \\
\text { Decisión o Declaración. }\end{array}$ & 14 & $32.5 \%$ \\
\hline & $\begin{array}{l}\text { Decisiones o Declaraciones en las que no aplica el factor } \\
\text { anterior. }\end{array}$ & 29 & $67.4 \%$ \\
\hline 17. & $\begin{array}{l}\text { Decisiones o Declaraciones cuyo contenido genera Incum- } \\
\text { plimiento del Parlamento Andino, en lo relacionado con } \\
\text { su función de armonización legislativa. }\end{array}$ & 7 & $16.2 \%$ \\
\hline & $\begin{array}{l}\text { Decisiones o Declaraciones en las que no aplica el factor } \\
\text { anterior. }\end{array}$ & 36 & $83.72 \%$ \\
\hline 18. & $\begin{array}{l}\text { Decisiones o Declaraciones que requieren leyes internas } \\
\text { que permitan su eficacia, frente al sistema de organización } \\
\text { administrativa descentralizado. }\end{array}$ & 22 & $51.1 \%$ \\
\hline & $\begin{array}{l}\text { Decisiones o Declaraciones en las que no aplica el factor } \\
\text { anterior. }\end{array}$ & 21 & $48.8 \%$ \\
\hline
\end{tabular}

Fuente: Decisiones del Parlamento Andino - Periodo 2008 a 2010 y Leyes Internas 
Ausencia de Interés de los Legislativos de los Estados Andinos por el Derecho Andino de la Integración: Al verificar las Decisiones emitidas por el Parlamento Andino durante el periodo 2008 a 2010, se pudo constatar que los legisladores de los países miembros hicieron caso omiso al contenido de las mencionadas Decisiones, estas ni siquiera fueron consideradas como aporte académico en el procedimiento legislativo. Lo anterior obedece fundamentalmente, a la ausencia de voluntad de las ramas legislativas del poder público de los Estados Andinos de contextualizarse en el marco del Derecho Andino de la Integración, y también a que el contenido de dichas Decisiones, en un porcentaje representativo, no amerita el debate legislativo en los respectivos Congresos o Asambleas Legislativas.

Incumplimiento por parte del Parlamento Andino de compromisos establecidos en algunas Decisiones: Al analizar el contenido de varias de las Decisiones emitidas por el Parlamento Andino, se pudo constatar el incumplimiento de compromisos por parte de dicho Órgano Internacional, relacionado con propuestas de homogenización legislativa y con la elaboración de proyectos sociales y políticos.

La Desarticulación del Sistema Andino de Integración (SAl): La efectividad de varias de las Decisiones del Parlamento Andino depende de la coordinación de las funciones asignadas a todos y cada uno de los Órganos e Instituciones que conforman el Sistema Andino de Integración (SAI). En razón a que hasta la fecha, en la Comunidad Andina (CAN) opera del fenómeno de la desarticulación del sistema, dicha circunstancia, en modo alguno, afecta la eficacia de las Decisiones del Parlamento Andino.

Ausencia de Coordinación de Funciones entre el Parlamento Andino y los Legislativos de los países miembros de la CAN: En el procedimiento de expedición de las Decisiones del Parlamento Andino se pudo constatar la ausencia de participación de los Legislativos de los Estados Andinos. Es de relevancia aclarar que si bien no se deben confundir las funciones de los Legislativos de los países miembros con las funciones asignadas al Parlamento Andino, en la actualidad, es necesaria la participación de los Congresos o Asambleas Legislativas de los Estados Andinos en las Sesiones Reglamentarias y Extra Reglamentarias del Parlamento Andino, en aras de que el proceso andino de integración se consolide como política de Estado, para lo cual, el apoyo de las ramas legislativas de los países miembros es de relevancia.

Ausencia de Legitimidad del proceso de integración andino: La población de los países miembros de la CAN no se identifica con la razón de ser de la integración andina y como consecuencia de ello, no consideran que las Decisiones de órganos comunitarios, como el Parlamento Andino, les permitan solucionar sus problemas económicos y sociales; lo anterior, aunado a que tan solo el $75 \%$ de los parlamentarios andinos son elegidos por elección popular, afecta la eficacia de las Decisiones que emita el órgano deliberante de la Comunidad Andina (CAN). 
Inexistencia de mecanismos coercitivos para dar cumplimento a las Decisiones del Parlamento Andino, como Órgano comunitario: Al verificar el Ordenamiento Jurídico Andino, se puede constatar la inexistencia de instrumentos de coerción para el cumplimiento de las Decisiones del Parlamento Andino. Lo anterior genera la imposibilidad práctica, de hacer exigibles las Decisiones del mencionado organismo internacional.

Relación Significativa entre la Supranacionalidad e Incumplimiento: La referenciada relación obedece a que los gobiernos de turno de los Estados miembros no otorgan relevancia al cumplimiento de los compromisos que surgen como consecuencia del ordenamiento jurídico andino, porque les preocupa más mantener sus compromisos internos, utilizando para ello, instrumentos de carácter nacional, que mecanismos de carácter supranacional y comunitario.

Ausencia de coordinación en las funciones del Parlamento Andino y algunas Decisiones emitidas por este: Al verificar el contenido de varias de las Decisiones del Parlamento Andino durante el periodo 2008 a 2010, se pudo constatar su no correspondencia con las atribuciones del Parlamento Andino; como quiera que dichos contenidos se enmarcan en temas que no son propios a los objetivos de la integración andina, o que se circunscriben al Derecho Interno, Derecho Internacional y Derecho Internacional Humanitario.

Reiteración del contenido de las Decisiones en las leyes de los Estados miembros de la CAN: Al interior de los Estados Andinos existen leyes que prevén el contenido de algunas de las Decisiones emitidas por el Parlamento Andino. Dicha circunstancia se configura en una clara confusión entre lo que debe ser el Derecho Andino de la Integración y el Derecho Interno, y a la vez, en un desgaste administrativo al interior del Parlamento Andino.

Omisión en el seguimiento de las Decisiones emitidas por el Parlamento Andino: Al verificar la estructura orgánica del Parlamento Andino no existe una instancia encargada de efectuar el seguimiento a las Decisiones que este Organismo emite; ello dificulta la eficacia de las mismas ante los Legislativos de los Estados Andinos.

Incumplimiento del Parlamento Andino en lo relacionado con su función de armonización legislativa: Al verificar el contenido de varias de las Decisiones del Parlamento Andino se pudo constatar que estas evidencian la intención de efectuar armonizaciones legislativas, tarea que jurídicamente resulta valedera desde el Parlamento Andino. En otras palabras, el contenido de varias de las Decisiones ha debido enmarcarse en propuestas de armonización legislativa, proyectadas y presentadas por el Parlamento Andino a la Comunidad Andina (CAN); actividad que en realidad no se cumplió, ya que el contenido de dichas Decisiones se limitó a efectuar exhortaciones a los países miembros, para que de manera independiente e individual configuren las políticas necesarias en el tema en particular. 
Las Decisiones del Parlamento Andino en el marco de la Jurisprudencia de las Altas Cortes de los países miembros:

En aras de determinar el grado de implementación de las Decisiones del Parlamento Andino durante el periodo 2008 a 2010 en la Jurisprudencia de las Altas Cortes de los países miembros, se anexa el siguiente cuadro y se procede con su análisis, el cual intenta corroborar el grado de implementación deficiente:

Tabla 2: Decisiones del Parlamento Andino en el marco de la Jurisprudencia de las Altas Cortes

\begin{tabular}{|c|c|c|}
\hline & $\begin{array}{c}\text { Número de } \\
\text { decisiones }\end{array}$ & Porcentaje \\
\hline 1. $\begin{array}{c}\text { Decisiones o Declaraciones de aplicación inmediata por } \\
\text { las Altas Cortes de los países andinos }\end{array}$ & 0 & $0 \%$ \\
\hline 2. $\begin{array}{l}\text { Decisiones o Declaraciones aplicadas con primacía por las } \\
\text { Altas Cortes de los países andinos }\end{array}$ & 0 & $0 \%$ \\
\hline 3. Decisiones o Declaraciones que permiten la solución de \\
conflictos jurídicos & 0 & $0 \%$ \\
\hline 4. $\begin{array}{l}\text { Decisiones o Declaraciones que fueron objeto de conoci- } \\
\text { miento a los magistrados de las Altas Cortes de los países } \\
\text { andinos }\end{array}$ & 0 & $0 \%$ \\
\hline 5. Decisiones o Declaraciones que fueron objeto de conoci- \\
miento de los particulares
\end{tabular}




\begin{tabular}{|l|c|c|}
\hline 9. $\begin{array}{l}\text { Decisiones o Declaraciones en las que las Altas Cortes } \\
\text { de los países miembros prefieren aplicar otro tipo de ins- } \\
\text { trumentos jurídicos en sus procesos ordinarios o con- } \\
\text { tenciosos, diferentes a las mencionadas Decisiones o } \\
\text { Declaraciones }\end{array}$ & 8 & $18.6 \%$ \\
$\begin{array}{l}\text { Decisiones o Declaraciones en la que no aplica el citado } \\
\text { factor }\end{array}$ & 35 & $81.3 \%$ \\
\hline $\begin{array}{l}\text { 10. Decisiones o Declaraciones que son consideradas por las } \\
\text { Altas Cortes de los países miembros como Recomenda- } \\
\text { ciones }\end{array}$ & 43 & $100 \%$ \\
\hline $\begin{array}{l}\text { 11. Decisiones o Declaraciones que evidencian mecanismos } \\
\text { de coercibilidad }\end{array}$ & 0 & $0 \%$ \\
\hline
\end{tabular}

Fuente: Decisiones del Parlamento Andino - Periodo 2008 a 2010 y Jurisprudencia de las Altas Cortes

Las Decisiones del Parlamento Andino no son de aplicación inmediata y con primacía en la jurisprudencia de las Altas Cortes de los países miembros. Al verificar el contenido de las Decisiones del Parlamento Andino se pudo corroborar que dicho contenido no amerita aplicación directa, inmediata y con prevalencia, en los procesos contenciosos y ordinarios que deben liderar las Altas Cortes de los países miembros. Lo anterior obedece en primer lugar a que el mencionado contenido se circunscribe a directrices de carácter general y programático, que no permite configurarse como herramienta jurídica aplicable por los Magistrados de las Altas Cortes; $y$ en segundo lugar, a que el contenido de varias de las Decisiones emitidas está ya previsto en leyes emitidas por los Legislativos de los países miembros, lo que genera como consecuencia que las Altas Cortes prefieran aplicar dichas leyes, respecto de las referenciadas Decisiones, en aras de garantizar el principio de legalidad.

Las Decisiones del Parlamento Andino no permiten la solución de Conflictos Jurídicos: El contenido de las Decisiones del Parlamento Andino no permiten la solución de los conflictos jurídicos entre particulares, y entre estos y el Estado. Lo anterior impide a las Altas Cortes de los países miembros aplicar dichas Decisiones en los procesos ordinarios y contenciosos.

Ausencia de conocimiento de las Decisiones del Parlamento Andino en la Rama Judicial de los Estados miembros. Al verificar las actas de las Plenarias y de las diferentes Comisiones del Parlamento Andino se evidenció la no participación de representantes de las ramas judiciales de los Estados andinos, lo que conduce a que los jueces y magistrados no tengan conocimiento sobre los temas que son objeto del respectivo debate parlamentario y de las Decisiones emitidas. 
Lo anterior, aunado al hecho de la ausencia de legalización de los procedimientos de publicación de las Decisiones del Parlamento Andino, afecta indiscutiblemente el poco nivel de influencia de las mencionadas Decisiones en el trabajo ordinario de las ramas judiciales de los países miembros.

Ausencia de conocimiento de las Decisiones del Parlamento Andino por parte de los particulares. En el proceso de expedición de las Decisiones del Parlamento Andino se evidenció la falta de participación de la población andina, lo que conlleva a que dicha población no tenga conocimiento sobre las mismas. Como consecuencia de ello, los particulares no pueden hacer valer el contenido de las mismas en los procesos judiciales en los que sean partes procesales.

Inexistencia de mecanismos coercitivos para dar cumplimento a las Decisiones del Parlamento Andino: Al verificar el Ordenamiento Jurídico Andino, se puede constatar la inexistencia de instrumentos de coerción para el cumplimiento de las Decisiones del Parlamento Andino. Lo anterior genera la imposibilidad práctica de hacer exigibles las Decisiones del mencionado organismo internacional, en el marco de las competencias de las Altas Cortes de los países miembros.

Las Decisiones del Parlamento Andino en el marco de las Cartas Políticas de los Países Miembros:

En aras de determinar el grado de implementación de las Decisiones del Parlamento Andino durante el periodo 2008 a 2010 en la Jurisprudencia de las Altas Cortes de los países miembros, se anexa el siguiente cuadro y se procede con su análisis, el cual intentará corroborar el grado de implementación deficiente:

\section{Tabla 3: Decisiones del Parlamento Andino en el marco de las Cartas Políticas de los Países Miembros}

\begin{tabular}{|c|c|c|}
\hline & $\begin{array}{c}\text { Número de } \\
\text { decisiones }\end{array}$ & Porcentaje \\
\hline 1. $\begin{array}{c}\text { Decisiones o Declaraciones que desde la perspectiva cons- } \\
\text { titucional son vinculantes }\end{array}$ & 0 & $0 \%$ \\
\hline $2 . \quad \begin{array}{l}\text { Decisiones o Declaraciones cuyo contenido evidencia co- } \\
\text { nexión directa, con las competencias que los países miem- } \\
\text { bros han cedido a la Comunidad Andina (CAN) }\end{array}$ & $35 \%$ \\
$\begin{array}{c}\text { Decisiones o Declaraciones cuyo contenido no evidencia } \\
\text { conexión directa, con las competencias que los países } \\
\text { miembros han cedido a la Comunidad Andina (CAN) }\end{array}$ & 8 & $18.6 \%$ \\
\hline
\end{tabular}




\begin{tabular}{|c|c|c|c|}
\hline 3. & $\begin{array}{l}\text { Decisiones o Declaraciones que son consideradas por las } \\
\text { Cortes Constitucionales o Tribunales Constitucionales de } \\
\text { los países miembros, con supremacía, prevalencia o pri- } \\
\text { macía }\end{array}$ & 0 & $0 \%$ \\
\hline 4. & $\begin{array}{l}\text { Constituciones Políticas de los Estados miembros que per- } \\
\text { miten dinamizar la eficacia de las Decisiones o Declaracio- } \\
\text { nes del Parlamento Andino }\end{array}$ & 0 & $0 \%$ \\
\hline 5. & $\begin{array}{l}\text { Decisiones o Declaraciones que requieren normas cons- } \\
\text { titucionales marco, que permitan la eficacia de las Decisio- } \\
\text { nes del Parlamento Andino, frente al sistema de organiza- } \\
\text { ción administrativa descentralizado }\end{array}$ & 22 & $51.1 \%$ \\
\hline & $\begin{array}{l}\text { Decisiones o Declaraciones que no requieren normas } \\
\text { constitucionales marco, que permitan la eficacia de las De- } \\
\text { cisiones del Parlamento Andino, frente al sistema de orga- } \\
\text { nización administrativa descentralizado }\end{array}$ & 21 & $48.8 \%$ \\
\hline 6. & $\begin{array}{l}\text { Constituciones Políticas de los Países miembros que prevén } \\
\text { la transferencia de competencias a la Comunidad Andina, } \\
\text { en los temas objeto de las Decisiones o Declaraciones }\end{array}$ & 0 & $0 \%$ \\
\hline 7. & $\begin{array}{l}\text { Decisiones o Declaraciones que evidencian mecanismos } \\
\text { coercitivos para su cumplimento, desde la perspectiva cons- } \\
\text { titucional }\end{array}$ & 0 & $0 \%$ \\
\hline 8. & $\begin{array}{l}\text { Decisiones o Declaraciones que son consideradas por los } \\
\text { Tribunales Constitucionales o Cortes Constitucionales de } \\
\text { los países miembros como Recomendaciones }\end{array}$ & 43 & $100 \%$ \\
\hline
\end{tabular}

Fuente: Decisiones del Parlamento Andino - Periodo 2008 a 2010, Constituciones Andinas y Jurisprudencia de los Tribunales o Cortes Constitucionales.

Desde la perspectiva constitucional, la Decisiones del Parlamento Andino no son obligatorias: Las Constituciones de los países miembros no prevén el carácter obligatorio del Derecho Comunitario Andino Derivado, y como consecuencia de ello, las Decisiones del Parlamento Andino, desde una interpretación gramatical o exegética a las Constituciones de los Estados andinos, no son obligatorias. 
Las Decisiones del Parlamento Andino no son de aplicación inmediata y con primacía en la jurisprudencia de los Tribunales Constitucionales o Cortes Constitucionales de los países miembros: Al verificar el contenido de las Decisiones del Parlamento Andino se pudo corroborar que dicho contenido no amerita aplicación directa, inmediata y con prevalencia, en los procesos constitucionales que deben liderar los Tribunales Constitucionales o Cortes Constitucionales de los países miembros. Lo anterior en razón a que el mencionado contenido se circunscribe a directrices de carácter general y programático, que no permiten configurarse como herramienta jurídica aplicable por los Magistrados de las Instituciones guardianas de las Cartas Políticas de los países andinos. Otro motivo que no permite la aplicación inmediata y con primacía de las Decisiones del Parlamento Andino, obedece a que el contenido de varias de las Decisiones emitidas está ya previsto en leyes emitidas por los Legislativos de los países miembros, lo que genera como consecuencia que dichos Tribunales prefieran aplicar dichas leyes, respecto de las referenciadas Decisiones, en aras de proteger el principio de legalidad.

Inexistencia de normas constitucionales en las Cartas Políticas de los países miembros que permitan dinamizar el Derecho Derivado Comunitario Andino: Al verificar las Constituciones Políticas de los países andinos, se puede constatar que no existen normas constitucionales que dinamicen el Derecho Derivado Comunitario Andino. Como consecuencia de lo anterior, no existen mecanismos constitucionales que permitan otorgar celeridad en la eficacia de las Decisiones de órganos comunitarios, como el Parlamento Andino.

Inexistencia de mecanismos coercitivos para dar cumplimento a las Decisiones del Parlamento Andino: Al verificar el Ordenamiento Jurídico Andino se puede constatar la inexistencia de instrumentos de coerción para el cumplimiento de las Decisiones del Parlamento Andino. Lo anterior genera la imposibilidad práctica de hacer exigibles las Decisiones del mencionado organismo internacional, en el marco de las competencias de los Tribunales Constitucionales o Cortes Constitucionales de los países miembros

Ausencia de conexión directa entre el contenido de las Decisiones del Parlamento Andino y las competencias que los países miembros han cedido a la Comunidad Andina, en las Cartas Políticas: Al analizar la normatividad constitucional de los países miembros, en lo relacionado al ejercicio de las competencias que los Estados andinos han supuestamente transferido a la Comunidad Andina (CAN), se puede constatar que las mismas se constituyen en normas abiertas, y a veces ambiguas, como quiera que las mismas no determinan específicamente qué temas y subtemas puntuales son los que pueden ser gestionados por la Comunidad Andina (CAN) y los criterios fácticos y en tiempo, para el desarrollo de las mismas.

Inexistencia en el Derecho Andino de la Integración del principio de jerarquía normativa: Si bien en un Estado constitucional de Derecho, los principios fundamentales del sistema de normas se encuentra contemplado en la propia Constitución, en los Tratados, Acuerdos y Protocolos que conforman el Ordenamiento Jurídico Andino, no hay referencia alguna al 
principio de jerarquía normativa. Es así como en el Derecho Andino de la Integración, la configuración del sistema de normas, y de cada categoría en particular, ha sido obra de la jurisprudencia comunitaria y de la Doctrina. Sin duda, tal circunstancia afecta profundamente el nivel de eficacia de las Decisiones del Parlamento Andino, de esta forma, no resulta claro determinar cuáles Decisiones o Resoluciones emitidas por los órganos e instituciones del Sistema Andino de Integración (SAI) prevalecen cuando se evidencian contradicciones de contenido en las mismas. Al respecto, parece lógico que no puedan tener igual rango las Decisiones de la Comisión de la Comunidad Andina, del Consejo Andino de Ministros de Relaciones Exteriores, del Parlamento Andino y las Resoluciones de la Secretaría General. En efecto, parece claro que la Decisiones citadas se incorporan al ordenamiento jurídico interno con la categoría de ley, mientras que las Resoluciones parecen tener la categoría de actos administrativos (Rodríguez, 2010); en todo caso, dicho supuesto no encuentra sustento en norma internacional alguna, sino en criterios jurisprudenciales y doctrinarios elaborados por cada uno de los países miembros, que por ello, no ofrecen univocidad en el criterio a aplicar en toda la Comunidad Andina (CAN).

\section{¿POR QUÉ LAS DECISIONES DEL PARLAMENTO ANDINO DEBEN SER OBLIGATORIAS?}

En aras de enfrentar los retos de la globalización, el desafío del proceso andino de integración debe ser lograr que el pueblo andino se comprometa con la consolidación de la integración andina (Secretaria General de la CAN, 2008). Lo anterior supone el involucramiento directo de la población andina, para lo cual se hace determinante por parte del Parlamento Andino (como Órgano representante de los intereses de la población andina), el trabajo de promoción y difusión del proceso andino de integración; enfatizando en la importancia que tiene este mecanismo para mejorar la calidad de vida de la población andina. En este orden de ideas, el Parlamento Andino representa para los Estados que conforman a la Comunidad Andina (CAN) amplias posibilidades de desarrollo de su política exterior. Los retos del Parlamento Andino son variados y de gran importancia en el contexto nacional e internacional y dependen en esencia de las políticas nacionales de desarrollo y de los respectivos instrumentos de política social y económica adoptados por los Estados Andinos (Salgado G, 2007).

Si quisiéramos analizar el fundamento por el cual las Decisiones del Parlamento Andino deben ser en la práctica de carácter obligatorio, muy seguramente tendría que afirmarse que la razón primigenia de dicha obligatoriedad, obedece a que el mencionado Órgano Internacional es el único órgano del Sistema Andino de Integración (SAI) que ofrece legitimidad en las Decisiones y Declaraciones que emite.

Las Decisiones del Parlamento Andino deben ser obligatorias porque de conformidad con el Acuerdo de Cartagena, en concordancia con el Protocolo de Trujillo y el Tratado Constitutivo del Parlamento Andino, dicho Órgano Internacional evidencia las siguientes capacidades: 
El Parlamento Andino es el órgano capacitado para superar la crisis del proceso andino de integración, al ser el órgano comunitario que ostenta de legitimidad al interior del Sistema Andino de Integración (SAI). Lo anterior le permite proponer iniciativas de orden económico, social, jurídico y político, que pretendan subsanar la mencionada crisis. El Parlamento Andino es el órgano capacitado de otorgar legitimidad al proceso de integración andina, al ser el único ente del Sistema Andino de Integración (SAI) cuyos miembros son elegidos por elección directa, lo cual permite amortiguar el papel, poco fructífero, que hasta la fecha los gobiernos andinos han desempeñado en la integración andina. Es en el referenciado contexto que resulta procedente afirmar que el Parlamento Andino es el órgano capacitado para preparar al pueblo andino hacia la verdadera integración, como quiera que este órgano se configura como el verdadero interlocutor de la población andina y los órganos e instituciones que conforman el Sistema Andino de Integración (SAI). En otras palabras, el Parlamento Andino es el órgano comunitario capaz de preparar a los Estados miembros en la integración social, jurídica y política, para luego aprovechar las bondades de la integración económica. En este sentido, dicho Organismo Internacional puede preparar a los países miembros para que se comporten en el marco de un fenómeno de integración, lo que supone mecanismos de obligatoriedad y coercibilidad en las Decisiones que emita. Normalmente, cuando se analiza el fenómeno de la integración andina, se hace desde la perspectiva económica y en este sentido, se enmarca la crisis de la Comunidad Andina (CAN) desde la referenciada perspectiva. Al respecto, se considera que antes de debatir sobre la integración económica en la Comunidad Andina, es necesario analizar si los Estados andinos están preparados política, social y jurídicamente, para asumir la referenciada integración. Lo anterior como quiera que para lograr la efectividad de una integración económica en los países andinos, es necesario que los Estados miembros, estén preparados política, social y jurídicamente para asumir los retos de la integración económica andina. Es en el referenciado contexto en el que adquiere importancia el Parlamento Andino, quien ostenta de la iniciativa de formular propuestas que permitan a los países miembros comportarse en el marco de un verdadero proceso de integración, gracias a la legitimidad que evidencia normativamente.

El Parlamento Andino es el órgano capacitado para matizar los efectos del fenómeno de la globalización en los países andinos. El fenómeno de la globalización ha generado un cambio de organización política y jurídica, sin que a la fecha los Estados andinos cuenten con elementos institucionales que garanticen una transición pacífica, equilibrada y justa hacia el mencionado cambio (Caballero \& Anzola, 1995). Frente a este inconveniente, órganos comunitarios como el Parlamento Andino, juegan papel de importancia, ya que los mismos pueden proponer con carácter vinculante, elementos que faciliten la citada transformación. En este sentido, y para efectos del proceso andino de integración, el Parlamento Andino, como órgano comunitario, se tipifica como organismo internacional con capacidad de contextualizar y preparar al pueblo andino frente al fenómeno de la globalización. Lo anterior supone prioritariamente, el compromiso del mencionado Órgano Internacional de formular propuestas de armonización legislativa al interior de la Comunidad Andina (CAN) que permitan contextualizar el Ordenamiento Jurídico Interno de los países miembros frente a la Globalización del Derecho. 
El Parlamento Andino es un órgano colaborador en el ejercicio de las nuevas funciones estatales: Es de amplia tradición dentro del constitucionalismo clásico, la importancia que se le ha atribuido al concepto fundamental de la división o separación de los poderes, el cual ha sido entendido esquemáticamente como el mecanismo que impide que las diversas funciones del poder se concentren en un solo órgano. El citado principio ha perdurado a lo largo de los siglos XIX, XX y hasta nuestros días, como uno de los principios básicos del constitucionalismo contemporáneo. Se trata de una directriz reguladora del Estado, el cual desde el punto de vista teórico resulta impecable, pero ya en la práctica no ha podido proyectarse cabalmente, puesto que resulta imposible su aplicación rígida y exacta, por las mismas necesidades sociales, económicas y políticas, con las cuales han tenido que enfrentarse los Estados (Montero, 2009); es por ello, que es factible dentro de la gestión estatal, la existencia de organismos internacionales comunitarios con funciones limitadas y excluyentes que apoyen el desarrollo social, económico y político del pueblo, y de esta manera, colaboren al ejecutivo y al legislativo en tareas de política internacional. Dentro de los citados organismos internacionales encontramos al Parlamento Andino, quien además de contribuir con el ejecutivo y el legislativo en la política exterior de los Estados andinos, es herramienta para el desarrollo de las relaciones internacionales, con el plus adicional de que las gestiones que adelante ostentan de legitimidad, atendiendo su naturaleza jurídica democrática y plural.

El Parlamento Andino es un órgano capaz de mejorar la calidad de vida del pueblo andino: si analizamos la situación y los avances de los países andinos en materia de desarrollo social se encuentra que los grandes retos que se han propuesto no se han podido alcanzar, y muchos de ellos no han trascendido del escrito a las acciones concretas. La situación de la mayoría de los Estados andinos es bastante compleja y con el transcurrir del tiempo parece que no mejora. Los índices de pobreza, desempleo, seguridad social, analfabetismo e inclusión social parecería que no disminuyeran. Dentro de este orden de ideas, la práctica integradora parece ser el ideal que permitiera a los países, tras previo consenso de unos objetivos comunes y claros, el crecimiento económico, político, social y un desarrollo equitativo. Bajo el citado contexto, la referenciada práctica integradora debe ser liderada por un órgano comunitario como el Parlamento Andino, quien de conformidad con la normatividad internacional evidencia capacidad de orientar y direccionar el proceso de integración andino con legitimidad

El Parlamento Andino es el instrumento de control político de los órganos e instituciones que conforman el Sistema Andino de Integración (SAI), ello supone Decisiones obligatorias sobre el particular, en aras de coordinar al mencionado Sistema. De conformidad con el Acuerdo de Cartagena, el Protocolo de Trujillo y el Protocolo Constitutivo del Parlamento Andino, se ha considerado a dicha entidad, como el órgano de control político en la Comunidad Andina (CAN), para lo cual cuenta con mecanismos de seguimiento, promoción y participación política, que a continuación se proceden a enunciar y que requieren de Decisiones obligatorias para su materialización: 
El Observatorio de Seguimiento de Integración Andina: el Observatorio de Seguimiento de Integración Andina permite llevar un seguimiento de las Directrices Presidenciales, en aras de contextualizar los avances y obstáculos del proceso de integración. Dicho Observatorio se materializa en una reunión de la Secretaría General del Parlamento Andino y los órganos e instituciones que conforman el Sistema Andino de Integración (SAI), en la que se pretende recaudar los informes de gestión de dichos órganos e instituciones, con la finalidad de elaborar con posterioridad, el informe temático, el cual es presentando ante las Comisiones del Parlamento, en aras de debatirlo en la Plenaria.

Observatorio Electoral del Parlamento Andino. Este instrumento de acción del Parlamento Andino se encarga de proteger y fortalecer los procesos electorales en la Subregión. El Observatorio Electoral del Parlamento Andino se materializa a través de la Misión Observadora del Parlamento Andino (MOPA), la cual esta institucionalizada como un instrumento de observación y análisis de los procesos electorales democráticos de la Subregión en cumplimiento del mandato institucional del Parlamento Andino de sustentar en la Subregión el pleno imperio de la democracia y el derecho a la libre autodeterminación de los pueblos. La MOPA, en este sentido, pretende: (i) contribuir a la consolidación de la democracia y la gobernabilidad en la Subregión; (ii) observar rigurosamente los procesos electorales de la Subregión, con el fin de contribuir al fomento de un clima de confianza, seguridad y credibilidad en el sistema electoral del país anfitrión y en la Subregión; (iii) analizar y evaluar los procesos observados teniendo como referente criterios de representación, libertad electoral, respeto del derecho al sufragio, normatividad y metodología utilizada, imparcialidad de la autoridad electoral, operatividad y eficacia de los sistemas de validación del voto, de conteo y expedición de resultados, y en general, de lo relativo al funcionamiento del componente institucional que implica un proceso de elecciones; (iv) colaborar con las autoridades gubernamentales, electorales y partidarias, y con la población en general, para asegurar la integridad, imparcialidad y confiabilidad del proceso electoral.

Derecho de petición: El Parlamento Andino ha considerado al derecho de petición no solo en su matiz de derecho fundamental, sino también como derecho de carácter político, esto es, como un derecho que permite a la población andina participar de las Decisiones que emita dicho Órgano Internacional. Es por lo anterior que con la finalidad de garantizar la iniciativa popular del pueblo andino, cualquier ciudadano de la Comunidad Andina, así como cualquier persona natural o jurídica que resida o tenga su domicilio en un Estado Miembro, tiene derecho a presentar ante el Parlamento Andino peticiones sobre los asuntos propios de los ámbitos de la Comunidad Andina (CAN), en aras de que las mismas sean debatidas al interior de la Mesa Directiva y/o Plenaria del Parlamento.

El Parlamento Andino es el órgano capacitado para articular el Sistema Andino de Integración (SAI): el conjunto de instituciones y órganos de la Comunidad Andina (CAN) se encuentran integrados en el Sistema Andino de Integración (SAI), cuya finalidad es permitir la coordinación 
efectiva entre sí, para profundizar la integración subregional andina, promover su proyección externa y robustecer las acciones relacionadas con el proceso de integración. El Protocolo de Trujillo creó la expectativa de poder contar con mecanismos que permitieran realizar la debida coordinación entre todos los organismos responsables de la integración subregional, lo cual en la realidad no se ha logrado, pues dicha coordinación se ha limitado a un rápido informe de cada organismo o institución presentado al interior del Parlamento Andino, sin que se produzca el necesario trabajo conjunto para profundizar las acciones que cada órgano e institución del Sistema Andino de Integración está desempeñando y lograr, de esta manera, la interacción esperada. Al Sistema Andino de Integración (SAI) le corresponde la evaluación de las contradicciones internas de la marcha del proceso, por ser el foro en que están representados todos los organismos responsables de su funcionamiento, esta debe ser una de sus funciones principales, la cual no se cumple por la desarticulación del referenciado Sistema, al no existir coordinación de las funciones de los órganos e instituciones que conforman dicho Sistema (Parlamento Andino, 2007). Es en el referido contexto en el que el Parlamento Andino, como órgano encargado de ejercer control político en los órganos e instituciones del Sistema Andino de Integración (SAI), debe crear instrumentos formales y materiales que garanticen la adecuada coordinación del mencionado Sistema, para lo cual requiere de Decisiones que sean lo suficientemente vinculantes al interior del mismo.

El Parlamento Andino es el órgano capacitado para la transformación del proceso de integración como política de Estado: al Parlamento Andino le corresponderá velar para que el proceso de integración no dependa de la voluntad política de los Gobiernos de turno, es decir, contando con el apoyo de los Congresos Nacionales, deberá impulsar iniciativas para que la integración subregional se convierta en una verdadera política de Estado y no de Gobierno, teniendo en cuenta que a raíz del surgimiento y avance de la globalización, los procesos de integración se convierten en elemento indispensable para que los países puedan intercambiar bienes, servicios, capitales y personas, incrementando al mismo tiempo su participación en el escenario internacional (Parlamento Andino, 2010, p. 11). Para que el proceso andino de integración se convierta en una política de Estado, es indispensable la correlación de funciones entre el Parlamento Andino y los órganos legislativos de los países miembros. Dicha correlación debe ser liderada por el órgano comunitario deliberante de la Comunidad Andina (CAN), esto es por el Parlamento Andino. Dicha correlación supone Decisiones acordadas entre el mencionado Órgano Internacional y los Legislativos de los Estados andinos, que produzcan impacto al interior de los países miembros, que no pueden circunscribirse a sugerencias o recomendaciones, sino que evidencien vinculatoriedad. El Parlamento Andino en respuesta a la atribución conferida por el Artículo 43 del Acuerdo de promover relaciones de cooperación y coordinación con los Legislativos de los Países Miembros, ha impulsando acciones orientadas a consolidar el Foro de Presidentes de los Poderes Legislativos del Área Andina (FOPREL), como un espacio de diálogo y cooperación parlamentaria, y como un mecanismo de acercamiento de los legislativos de los Estados miembros al proceso de integración andino, el cual busca, entre otros aspectos, una mayor vinculación, cooperación y coordinación de estrategias legislativas y de políticas, para el 
tratamiento de los temas de la agenda regional andina (Instituto de Altos Estudios para la Integración y Desarrollo Legislativo, 2009).

El Parlamento Andino, de conformidad con el Artículo 43 del Acuerdo de Cartagena, es el órgano capacitado para proponer propuestas de armonización legislativa en la Comunidad Andina (CAN), lo cual supone Decisiones vinculantes del mismo, en el procedimiento de armonización.

El Parlamento Andino está capacitado para superar las limitaciones de la democracia preexistente en los espacios nacional y local, como quiera que dicho Órgano está facultado para promover la participación en el espacio regional, entre otras razones, por ser de conformidad con el Acuerdo de Cartagena el Órgano encargado de sustentar la democracia en los países miembros. Por lo anterior, es un Órgano capaz de fortalecer la democracia representativa y participativa en los países andinos. Al respecto es pertinente anotar que la generalizada insatisfacción con la representación democrática es un elemento central de la crisis de la democracia en los países andinos (Mainwaring \& Bejarano, 2008, p.31). Es evidente el desgaste en el sistema democrático representativo de los países andinos (Pacheco, 2000). Frente a dicha circunstancia, el Parlamento Andino como órgano representante de la población andina, puede proponer soluciones que subsanen la situación referenciada. Lo anterior supone la necesidad de asegurar la participación y el control ciudadano en el Sistema Andino de Integración (SAI) a través del Parlamento Andino, con la finalidad de lograr que el pueblo participe en el ejercicio de las competencias que han sido cedidas por los Estado miembros a la Comunidad Andina (CAN), ya que las mismas son gestionadas por órganos que no son elegidos por elección popular.

\section{CONCLUSIONES}

La integración andina puede ser considerada hoy una utopía, pero si se aplicase una matriz de reconocimiento de la necesidad del cambio, es indudable que se convertiría en el ideal hacia el cual debemos dirigirnos, cuando estén dadas todas las condiciones necesarias para lograr establecerlo como una realidad. Dentro de las referenciadas condiciones está el replanteamiento del papel del Parlamento Andino en el ordenamiento jurídico de los países miembros y en la Comunidad Andina (CAN)

La integración andina requiere, como presupuesto de existencia, la participación del pueblo andino para cumplir con sus objetivos, y de esta manera, lograr su consolidación. En la citada tarea, el Parlamento Andino juega papel de relevancia dado que es el único órgano del Sistema Andino de Integración (SAI) que evidencia legitimidad en su estructura orgánica.

Al interpretar jurídicamente el Tratado Constitutivo del Parlamento Andino en concordancia con las normas que conforman el Derecho Andino de la Integración, se puede constatar que las Decisiones emitidas por el citado Órgano Internacional, evidencian la característica de 
obligatoriedad; sin embargo, en la práctica no se observa dicha característica, en razón a la interpretación gramatical que se ha efectuado al mencionado Tratado, el cual considera a las Declaraciones de voluntad del órgano deliberante de la Comunidad Andina (CAN) como recomendaciones.

Al analizar las Decisiones del Parlamento Andino en el marco de las Constituciones Andinas, las leyes internas de los países miembros y la jurisprudencia de las Altas Cortes de los Estados andinos, se puede constatar que el nivel de implementación de las mencionadas Decisiones es deficiente, entre otros aspectos, por la falta de coordinación de las competencias propias del Derecho Interno con las del Derecho Comunitario Andino.

Para que las Decisiones del Parlamento Andino produzcan los efectos deseados, es necesario gestionar al interior de la Comunidad Andina (CAN) una adición al Tratado Constitutivo del dicho Órgano, en el que se le atribuya la facultad de codecisión en el procedimiento de expedición de la normatividad comunitaria. A su vez, en los Órganos e Instituciones que conforman el Sistema Andino de Integración, es necesario que dicha Organización internacional ejerza a plenitud su papel de órgano de control político en la Comunidad Andina.

\section{BIBLIOGRAFÍA}

- Aranciba G. (2009). Integración y supranacionalidad: soberanía y derecho comunitario en los países andinos. Perú, Lima.: Secretaria General de la CAN y Programa de Cooperación Andina a Bolivia / PCAB.

- $\quad$ Barberis J. (1973). Fuentes del Derecho Internacional, La Plata, Argentina.: Platense.

- Barros Ch. (1989). Atribuciones del Parlamento Andino como Órgano Principal del Acuerdo de Cartagena y Orientador del Proceso de Integración Subregional. Revista: Integración Latinoamericana. Buenos Aires. No. 146-147 (junio-julio) (p.68)

- Caballero S \& Anzola G. (1995). Teoría Constitucional. Bogotá. Colombia.: Temis.

- De Cabo C. (2000). El Concepto de ley. Madrid. España.: Trotta

- Díaz R. (1982). La Convención de Viena sobre el Derecho de los Tratados y los Procedimientos Técnicos de Formación de las Diversas categorías de normas, Santiago de Chile, Chile.: Sociedad Chilena de Derecho Internacional, Estudios.

- Diez H. (1998). La Posición del Derecho Internacional en el Ordenamiento Comunitario. Madrid, España.: Mc Graw Hill. 
- Gómez A. (2010). Institucionalidad y Problemáticas de la Comunidad Andina de Naciones. Revista Académica y Cultural Fundación Politécnico GranColombiano Institución Universitaria. No. 10 Enero - Junio de 2010.

- Guardia E \&Delpech M. (1970). El Derecho de los Tratados y la Convención de Viena de 1969, Buenos Aires, Argentina.: Edit: La Ley.

- Herdegen M. (2005). Derecho Internacional Público, Universidad Nacional Autónoma de México. Ciudad de México, México.: Konrad Adenauer Stiftung.

- Instituto de Altos Estudios para la Integración y el Desarrollo Legislativo (IDL). (2009). "Propuesta de reforma a la Comunidad Andina". Bogotá, Colombia.: Parlamento Andino.

- Jiménez E. (1980). El Derecho Internacional Contemporáneo, Madrid, España.: Tecnos.

- Mainwaring S \& Bejarano A. (2008). La Crisis de la Representación Democrática en los Países Andinos. Bogotá, Colombia.: Grupo Editorial Norma

- Martínez D. (2008). La Integración en el Nuevo Constitucionalismo Latinoamericano en Crisis y Perspectiva Comparada de los Procesos de Integración, Segunda Jornada Cátedra Jean Monnet en Colombia, Universidad Externado de Colombia. Edit: Eric Tremolada Álvarez, Bogotá, Colombia

- Montero P. (2009). El Proceso Andino de Integración. Rescate del Pensamiento Latinoamericano. Revista del Parlamento Andino Vol V.: Parlamento Andino. Bogotá. Colombia. (p.5)

- Moyano C. (1985). La Interpretación de los Tratados Internacionales. Montevideo, Uruguay.: De Palma.

- Pacheco M. (2000). Los órganos de la Comunidad Andina y su Papel en el Logro efectivo de la Participación Civil en el proceso de integración. Articulo extraído el 20 de abril de 2011 de $w w w / / c o m u n i d a d a n d i n a . o r g$

- Parlamento Andino. (2007). Estudio sobre Reforma Institucional en la Comunidad Andina. Bogotá, Colombia.: Centro Andino de Investigación, Capacitación y Desarrollo Legislativo CADEL.

- Parlamento Andino. (2010). El ABC de las Elecciones Directas. Edición 1, Volumen 1. Bogotá, Colombia.: Edit: Parlamento Andino.

- Pérez L. (2000). Los principios básicos del Derecho Comunitario en las Constituciones Venezolanas de 1961 y 1999, recuperado el 15/03/07 de www.comunidadandina.org/ 
bda/docs/VE-INT-0008.pdf, en Palomares García Jose Ricardo. (2008). Comunidad Andina: Es vinculante el Derecho Comunitario?. Revista Vialnveniendi et ludicandi - Núm. 5, Mayo 2008. Documento Extraído el 20 de noviembre de 2010 de http://vlex.com/vid/42489356

- Perotti A. (2007). Habilitación Constitucional para la Integración Comunitaria. Buenos Aires, Argentina.: Jurua.

- Pescatore P. (1973). Derecho de la Integración: nuevo fenómeno de las relaciones internacionales. Buenos Aires, Argentina.: INTAL

- Ponce de León E. (2001). Temas de derecho comunitario ambiental andino. Bogotá, Colombia.: Universidad Externado de Colombia.

- Ramírez A. (2008). Recopilación Jurisprudencial de la Corte Constitucional de Colombia sobre Tratados de Comercio Internacional. Bogotá, Colombia.: Fundación Konrad Adenauer y Corporación Pensamiento Siglo XXI. (p. 110)

- Quindimil J. (2006). Instituciones y Derecho de la Comunidad Andina. Bogotá, Colombia.: Tirant lo Blanch. (pp. $175-176,181$ )

- Rodríguez L. (2010). El Derecho Administrativo frente a la internacionalización del Derecho y en particular frente al Derecho Comunitario. Documento extraído el 20 de diciembre de 2010 de http://vlex.com/vid/77329889

- Salgado G. (2007). El Grupo Andino. Quito, Ecuador.: Corporación Editora Nacional

- Salgado W. (2007). La Crisis de la Integración Andina. Revista Indoamerica. Revista de Integración Andina. Articulo Publicado el 6 de Noviembre de 2007. Revista Editada por WilbertBendezu. Lima. Perú.

- Sánchez S. (2000). La integración y la Constitución Política de Bolivia, recuperado el 20/ 03/07 de http://www.comunidadandina.org/bda/docs/BO-INT-0003.pdf, en Palomares García José Ricardo. (2008). Comunidad Andina: ¿Es vinculante el Derecho Comunitario? Revista Vialnveniendi et ludicandi - Núm. 5, Mayo 2008. Documento Extraído el 20 de noviembre de 2010 de http://vlex.com/vid/42489356

- Secretaría General de la CAN, (2008). Una Comunidad Andina para los Ciudadanos: Un proyecto para la integración integral de nuestros pueblos. Lima, Peru.: Edit: CAN.

- Tangarife M. (2002). Derecho de la Integración en la Comunidad Andina. Bogotá, Colombia.: Baker \& McKenzie 
- Tremps P. (1994). Constitución Española y Comunidad Europea. Madrid, España.: Ariel. (p. 39).

- Vacchino, J. (1990). La Dimensión Parlamentaria de los Procesos de Integración Regional. Tomo I. BID. Instituto para la Integración de América Latina. Buenos Aires, Argentina.: Depalma Buenos Aires. (p.9)

- Visscher Ch. (1963). Problems d"interpretationjudiciaire en Droit International Public, Paris, Pedone. P. 14, en Ernesto de la Guardia y Marcelo Delpech, el Derecho de los Tratados y la Convención de Viena de 1969, Buenos Aires.: La Ley, p. 311 